\title{
Tsafon
}

Revue d'études juives du Nord

$81 \mid 2021$

Des synagogues à travers les âges Lieux de prières, lieux d'études et autres fonctions

\section{Baum Thomas et Vanden Daelen Veerle La Shoah et les droits humains, catalogue de l'exposition permanente}

Danielle Delmaire

\section{OpenEdition}

Journals

Édition électronique

URL : https://journals.openedition.org/tsafon/4035

DOI : $10.4000 /$ tsafon.4035

ISSN : 2609-6420

Éditeur

Association Jean-Marie Delmaire

Édition imprimée

Date de publication : 1 juillet 2021

Pagination : 164-165

ISSN : 1149-6630

Référence électronique

Danielle Delmaire, «Baum Thomas et Vanden Daelen Veerle La Shoah et les droits humains, catalogue de l'exposition permanente », Tsafon [En ligne], 81 | 2021, mis en ligne le 01 juillet 2021, consulté le 16 septembre 2021. URL : http://journals.openedition.org/tsafon/4035 ; DOI : https://doi.org/10.4000/ tsafon. 4035

Ce document a été généré automatiquement le 16 septembre 2021.

Tsafon. Revues d'études juives du Nord 


\title{
Baum Thomas et Vanden Daelen Veerle La Shoah et les droits humains, catalogue de l'exposition permanente
}

\author{
Danielle Delmaire
}

\section{RÉFÉRENCE}

Baum Thomas et Vanden Daelen Veerle (dir. de publication), La Shoah et les droits humains, catalogue de l'exposition permanente, Gand,éditions Marot-Tijdsbeeld et Malines Kazerne Dossin, 2020, 480 pages, 680 illustrations, prix non indiqué.

1 Cet ouvrage est le catalogue de l'exposition permanente du musée de la Caserne Dossin à Malines dont le thème principal est la Shoah mais s'y ajoutent des réflexions sur les droits humains en général et partout dans le monde. Huit collaborateurs ont aidé les deux auteurs pour réaliser ce volumineux catalogue, en hommage à Maxime Steinberg, le premier historien belge qui a travaillé sur la déportation des Juifs de Belgique.

2 Le catalogue donne à voir l'essentiel de l'exposition. Il repose sur la publication d'abondantes photos d'époque et la reproduction de documents d'archives ou d'objets comme des cartes d'identité ou d'alimentation, et encore de caricatures. Les textes sont peu développés et, à part quelques pages de présentation des différentes parties du livre, ils sont réduits à la l'explication des illustrations.

3 L'ouvrage repose sur trois parties: les masses (une centaine de pages), l'angoisse (presque 350 pages) et la mort (un peu plus d'une centaine de pages). Ce sont donc prioritairement les conditions de survie pour contrer la persécution qui ont retenu l'attention des auteurs.

4 Les masses. L'exposition s'attarde sur des photos de foule: prisonniers politiques allemands des années 1930, militants nazis rassemblés dans des stades, rassemblements 
dans les rues des villes allemandes en soutien au dictateur ou lors des exactions contre les Juifs. En opposition d'autres photos montrent des défilés du $1^{\mathrm{er}}$ mai organisés par des militants juifs avec des banderoles en yiddish. En parallèle avec l'actualité, une photo d'une barque surchargée de réfugiés, isolée en pleine mer, impressionne.

5 L'angoisse. L'abondance des mesures répressives occupe ces 350 pages. L'accumulation des ordonnances, l'enregistrement des Juifs avec les listes qui s'allongent, le marquage des entreprises et des magasins, les étoiles cousues sur les vêtements, les cartes d'identité estampillées Jood et Juif, les spoliations sont autant de sources d'angoisse pour les Juifs de Belgique durant toute la guerre. Des photos font découvrir les terribles conditions de détention au fort de Breendonk et à la caserne Dossin. S'ajoute la convocation pour un travail forcé dans les camps pour Juifs (Judenlager) du Boulonnais dans le nord de la France. Enfin les rafles et la clandestinité se superposent à toutes ces mesures génératrices d'angoisse. Les cartes de la répartition des refuges pour les Juifs sont hélas peu lisibles (p. 280-283). Cette partie centrale, et la plus importante, rassemble, sur une cinquantaine de pages, plusieurs portraits de «vies volées». En parallèle avec l'actualité, plusieurs photos rappellent les discriminations entretenues par l'État envers les populations colonisées, le régime d'apartheid des États-Unis et les violences faites envers les Noirs.

6 La mort. Cette partie respecte la chronologie des mises à mort opérées par le régime nazi en publiant des photos de personnes condamnées car handicapées ou ces «vies sans valeur »! Elle poursuit en insistant sur la mort omniprésente dans les ghettos et sur les exécutions de masse qui ravagent les communautés juives d'Europe de l'est. Elle se focalise aussi sur la «mort industrielle » pratiquée dans les camps d'extermination. Les auteurs s'attardent sur la cruauté morbide du système concentrationnaire en associant des photos des gardiens des camps, heureux de vivre et insouciants de bonheur! Mais la mort concerne aussi les bourreaux. Le «châtiment" s'abat sur les dignitaires nazis que des photos montrent lors du procès de Nuremberg, comme il s'abat sur Eichman jugé à Jérusalem. En parallèle avec l'actualité, des clichés n'oublient pas les morts dus aux travaux forcés dans les colonies, en Afrique ou partout ailleurs où les droits humains sont bafoués.

7 Si les textes sont plutôt succincts, l'iconographie est très ample et très riche. Le catalogue donne beaucoup à voir s'il ne donne pas beaucoup à lire. Et c'était sans doute le but des auteurs d'une exposition. Il peut être assimilé à une encyclopédie visuelle même si certaines photos ont pu être remises en cause par la critique fine de Tal Bruttmann. 